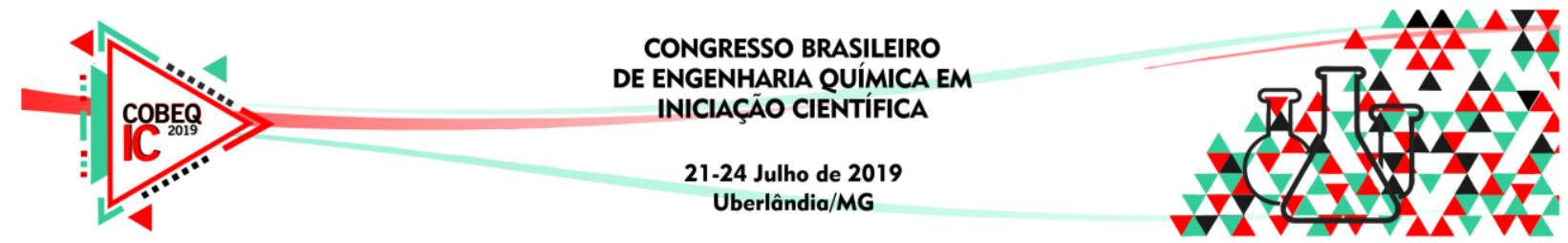

\title{
PRODUÇÃO E ANÁLISES FÍSICO-QUÍMICAS DA AGUARDENTE OBTIDA A PARTIR DO DOCE DO BURITI
}

\author{
R.J. de L. CORRÊA ${ }^{1}$ e E. de S. FERREIRA Jr${ }^{1}$ \\ ${ }^{1}$ Faculdade Pitágoras, Coordenação de Engenharia Química \\ E-mail para contato: raimundointelectual@gmail.com
}

\begin{abstract}
RESUMO - Aguardente é uma bebida com teor alcoólico entre 38 e 54\% em volume. O doce de buriti é um produto fabricado a partir do buriti (mauritia flexuosa) que é um fruto característico da região norte/nordeste. Este trabalho teve como objetivo a produção e a análises físico-química da aguardente obtida do doce do buriti. Foram realizadas as análises físico-químicas de $\mathrm{pH}$, teor alcoólico real, acidez volátil, ésteres totais, extrato seco total e ${ }^{\circ}$ Brix seguindo a metodologia do Instituo do Adolfo Lutz. De acordo com os resultados foi verificada, a boa qualidade de bebida.
\end{abstract}

\section{INTRODUÇÃO}

Antes de ser um produto econômico, agroindustrial, uma mercadoria, um artigo comercializável, a cachaça é uma façanha do povo brasileiro, uma obra da nossa história, uma autêntica expressão de nossa cultura. Ela integra a identidade do povo brasileiro, faz parte de seu patrimônio material e imaterial, habita inúmeras manifestações da cultura brasileira, especialmente o universo popular e folclórico, ora como tema ou motivo, como elemento ou ornamento, ora sugerindo a ambiência e o espírito do fato cultural. Está presente nas artes, na religiosidade, nas festas, na culinária, medicina, música, literatura, enfim, no imaginário e no cotidiano (FOLEGATI, 2013).

Pela legislação, a aguardente é definida como a bebida com graduação alcoólica de $38 \%$ a $54 \%$ em volume, obtida através do rebaixamento do teor alcoólico do destilado alcoólico simples ou pela destilação do mosto fermentado, podendo ser obtido a partir de vários produtos vegetais (BRASIL, 2009).

O Buriti (Mauritia flexuosa), é fruto que possui em seu mesocarpo uma camada de massa oleosa, de cor alaranjada, envolvendo o endocarpo, rico em pigmento carotenóide (Roche Nutri-Inorme, Carotenóides) (INSTITUTO ADOLFO LUTZ, 1977). O doce de buriti é feito concentrando-se uma mistura de polpa, açúcar e água.

Considerando ampliar a sua utilização comercial e atribuir uma importância maior ao doce do buriti, produzindo uma nova finalidade para esta matéria-prima, que geralmente é utilizada como alimento, deram suporte ao desenvolvimento deste trabalho, propondo o desenvolvimento do destilado, através da fermentação biológica utilizando como fermento a espécie Saccharomyces cerevisiae, uma levedura muito empregada na indústria alimentícia. 


\section{MATERIAIS E MÉTODOS}

As etapas realizadas para o processo de obtenção da aguardente a partir do doce do buriti são apresentadas no seguinte fluxograma.

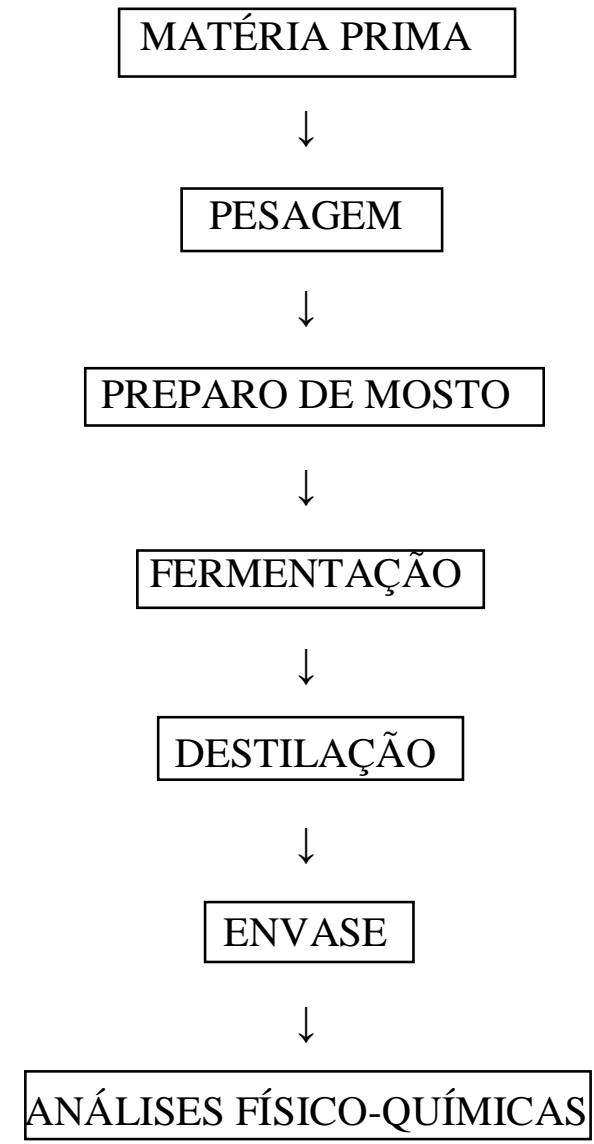

A matéria utilizada foi o doce do buriti (Mauritia flexuosa). Ele foi adquirido no Mercado Central de São Luís - MA, sendo que foram utilizadas 3 caixas de doce de buriti contendo cada uma 400g, como mostra a figura 1.

Figura 1 - Doce de Buriti

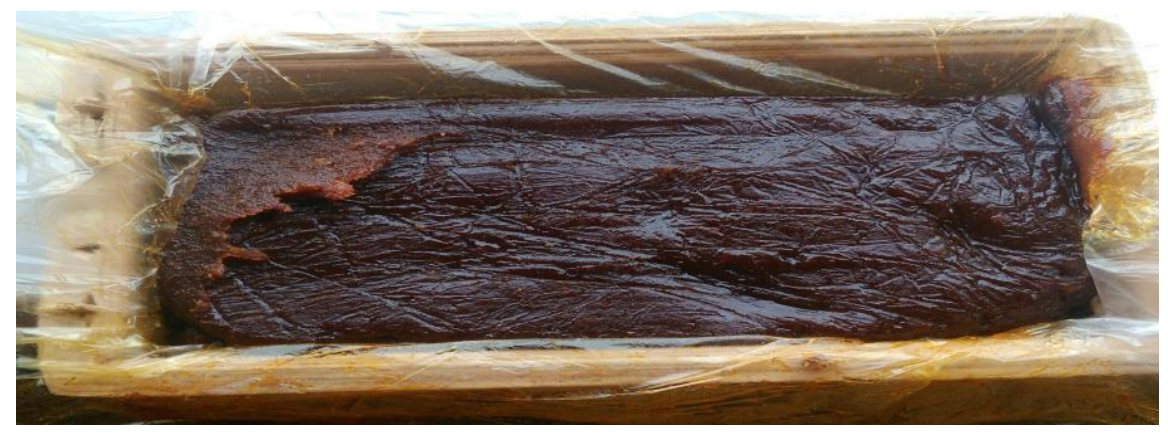




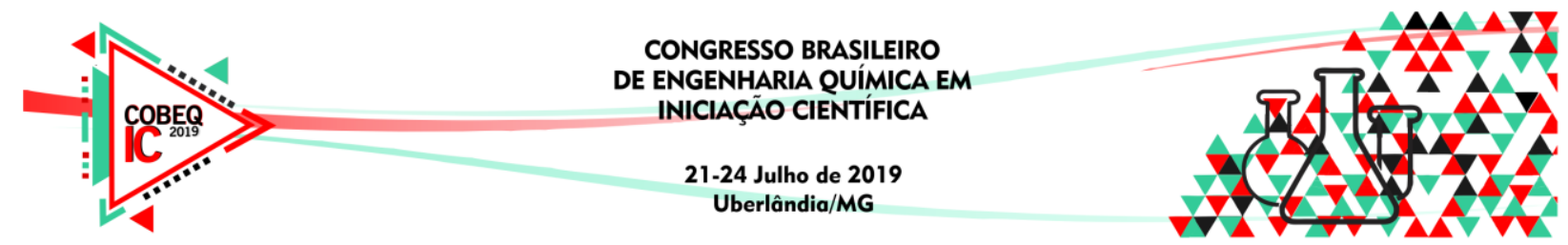

Os experimentos foram realizados no Laboratório de Bebidas do Instituto Federal de Educação, Ciência e Tecnologia do Maranhão - IFMA, Campus Maracanã. O doce foi conservado em uma temperatura de $21^{\circ} \mathrm{C}$, ele foi pesado no momento de cada análise.

Mosto é o termo empregado em tecnologia de bebidas alcoólicas para definir um líquido açucarado apto a fermentar (VENTURINI FILHO, 2005). Foi utilizado 1,2kg de doce de buriti para $20 \mathrm{~L}$ de água, sendo necessário adicionar $1,85 \mathrm{~kg}$ de açúcar para atingir o Brix padrão e após foi inserido o fermento biológico.

A fermentação teve duração de 72 horas em temperatura ambiente com $\mathrm{pH}$ de 4,5, a ausência da produção de gás foi o indicativo do término do processo.

A destilação, processo físico para separações químicas, consiste em aquecer um líquido até sua passagem para o estado gasoso, que em seguida retorna ao estado líquido por meio de resfriamento, objetivando especialmente a purificação ou formação de novos produtos por decomposições de frações. Na produção de cachaça, deve-se considerar ainda a formação de componentes em virtude de reações, que ocorrem dentro do alambique de cobre. É a etapa responsável por separar todas as substâncias de interesse formadas pela fermentação. Por este motivo é considerada de extrema importância para obtenção de uma cachaça de qualidade (BORTOLETTO et. al, 2013). A destilação deste processo durou 8 horas na temperatura entre $85^{\circ}$ e $90^{\circ} \mathrm{C}$, mantendo sempre o controle.

Após a obtenção da bebida o pH obtido foi de 4,5, faixa que atende a legislação. A aguardente de doce de buriti foi armazenada em um frasco de vidro para repouso, após essa etapa foram realizadas as análises físico-químicas.

\section{RESULTADO E DISCUSSÃO}

Os principais dados relacionados ao processo de fermentação e destilação estão na tabela 1 .

Tabela 1 - Produção da Aguardente

\begin{tabular}{|l|c|c|c|c|c|}
\hline & Brix & Volume (L) & $\mathrm{pH}$ & $\begin{array}{l}\text { Teor alcoólico } \\
\text { aparente }\end{array}$ & $\begin{array}{l}\text { Teor } \\
\text { alcoólico } \\
\text { real }\end{array}$ \\
\hline $\begin{array}{l}\text { Antes da } \\
\text { fermentação } \\
\text { (mosto) }\end{array}$ & 14 & 20 & 4,5 & - & - \\
\hline $\begin{array}{l}\text { Após ás } \\
\text { fermentação d }\end{array}$ & 5 & - & 4,5 & - & - \\
\hline Após a destilação & - & 19,050 & 4,5 & 43 & 39,8 \\
\hline
\end{tabular}




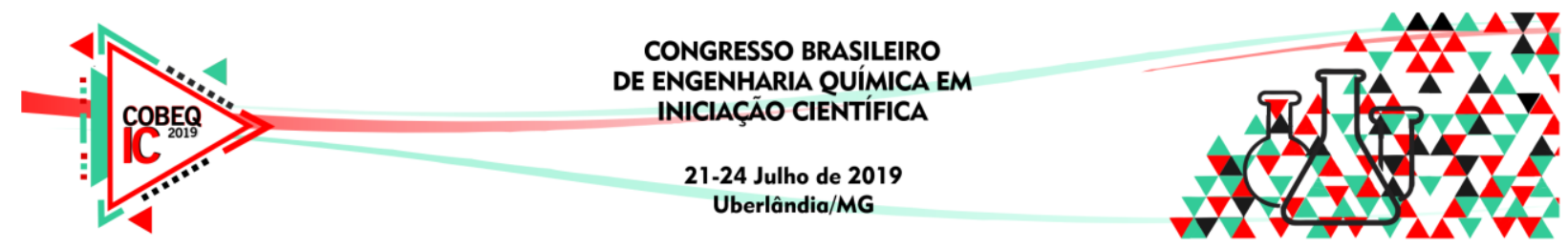

O Brix do mosto significa a porcentagem em massa de sólidos solúveis na solução, em sua maioria a sacarose. O brix inicial estava no grau ideal para início de fermentação $\left(14^{\circ}\right.$ $16^{\circ}$ ), assim como o brix final $\left(4^{\circ}-6^{\circ}\right)$ (REZENDE et. al., 2013). Neste experimento, os valores do Brix ficaram dentro do padrão.

A elevação da temperatura acima de $32^{\circ} \mathrm{C}$ traz muitas desvantagens, entre elas: a elevação das perdas de álcool por evaporação, diminuindo com isto o rendimento industrial (VENTURINI FILHO, 2005). As perdas que ocorreram no processo foram devido ao processo de destilação, e a falta de controle de algumas etapas da produção, ocorrendo a diminuição do volume.

A legislação vigente no Brasil regulamenta as aguardentes de acordo com a matériaprima utilizada (QUEIROZ et. al., 2014). A legislação atual não abrange as aguardentes produzidas a partir dos doces.

Os dados referentes às análises físico químicas estão na tabela 2.

\begin{tabular}{|c|c|c|}
\hline & Média \pm Desvio Padrão & $\begin{array}{l}\text { Padrão de identidade e } \\
\text { qualidade estabelecido pela } \\
\text { legislação brasileira }\end{array}$ \\
\hline $\begin{array}{c}\text { Acidez volátil (em ácido } \\
\text { acético, em mg/100ml de } \\
\text { álcool anidro) }\end{array}$ & $1,3 \pm 0,1$ & Máx. 150 \\
\hline $\begin{array}{c}\text { Ésteres Totais (em mg/100ml } \\
\text { de a.a) }\end{array}$ & $2,6 \pm 0,2$ & - \\
\hline $\begin{array}{c}\text { Extrato Seco Total (g/l) } \\
\text { Sect }\end{array}$ & $0,0018 \pm 0,0008$ & - \\
\hline
\end{tabular}

As características gerais de aguardente são dadas pela somatória de seus congêneres. Assim, análises como extrato seco são úteis para avaliar teores de sólidos solúveis e podem ser um indicativo da necessidade de determinação de açúcares redutores totais (MARTINS et al, 2007).

Os teores de acidez volátil dependem de fatores como o adequado controle do tempo e da temperatura durante o processo fermentativo, tipo de levedura utilizada, manejo do mosto e, principalmente, higiene no processo de fabricação (CARDOSO, 2019). Os valores médios de acidez volátil encontrados situaram-se abaixo do limite máximo de $150 \mathrm{mg}$ de ácido 


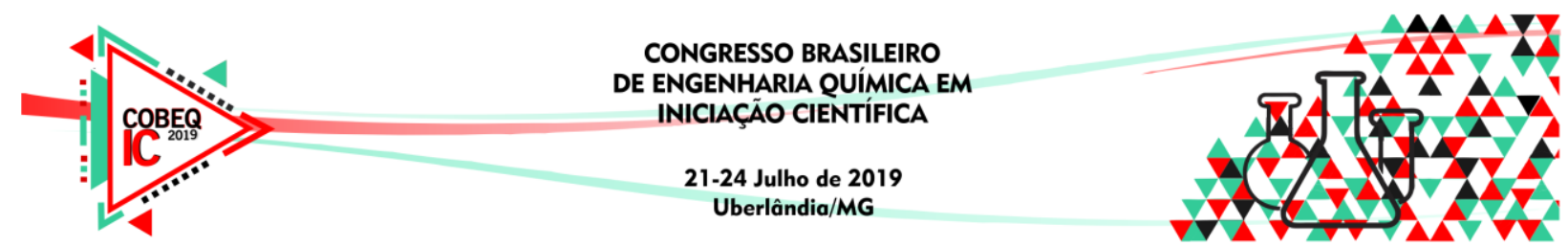

acético por $100 \mathrm{ml}$ de álcool anidro, conforme estabelece a legislação. A acidez volátil foi determinada através da equação 1 .

$$
A v=\frac{E q \times n \times N}{10 \times V}
$$

Quanto aos ésteres totais o valor obtido foi de $2,6 \mathrm{mg} / 100 \mathrm{ml}$ de álcool anidro. Responsáveis pelo aroma que a aguardente adquire com o envelhecimento são formados em reações de esterificação entre álcoois e ácidos carboxílicos durante o processo oxidativo. $\mathrm{O}$ cálculo do teor de ésteres totais foi realizado com a equação 2.

$$
E a a=\frac{n \times N \times 8,8 \times 100}{V \times G R} \times 1000
$$

O resultado encontrado para o parâmetro de extrato seco total foi de $0,0018 \mathrm{~g} / \mathrm{L}$ de álcool anidro, a legislação vigente não possui padrão de extrato seco para aguardente. A equação 3 foi utilizada para determinar extrato seco total.

$$
E s=40 \times(a-b)
$$

\section{CONCLUSÃO}

Foi possível o desenvolvimento da aguardente a partir do doce do buriti, possibilitando uma nova alternativa de produto no mercado através de um matéria-prima regional.

Através dos resultados obtidos, constatou-se que não há viabilidade do processo em grande escala.

Em relação aos atuais padrões de identidade e qualidade para a aguardente, não há padrões específicos para uma aguardente produzida a partir do doce de um fruto.

\section{REFERENCIA}

BARACHO, Rafael de Albuquerque. Estudo da Produção de Aguardente de Laranja em Escala Laboratorial. Disponível em: https://www.gvaa.com.br/revista/index.php/CVADS/article/view/976. Acesso em: 11 abril 2019.

BORTOLETTO, A.M.; LIMA, F.V. de; ALCARDE, A.R.; SOUZA, L.M. de. Produção de Cachaça de Qualidade. Disponível em: 〈http://www.appca.com.br/publication.pdf〉. Acesso em: 27 março 2019. 


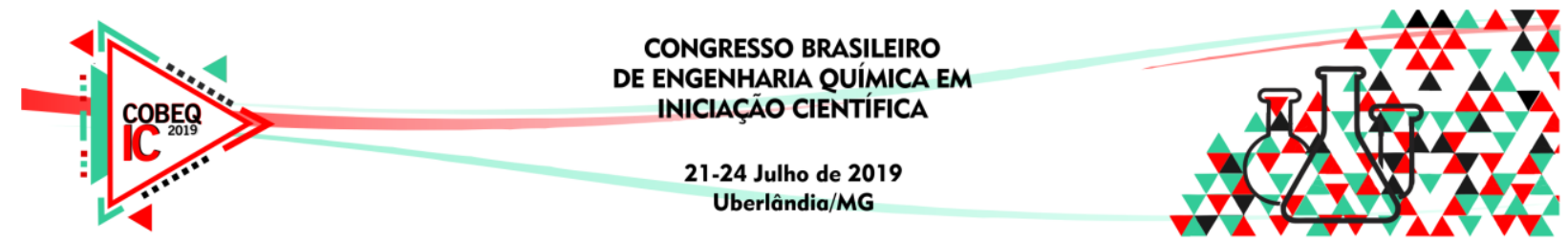

BRASIL. Decreto $n^{\circ}$ 6871, de 14 de junho de 2009. Dispõe sobre a padronização, a classificação, o registro, a inspeção, a produção e fiscalização de bebidas. Legislação de bebidas. [S.I.], p.10, jun. 2009. Disponível em: <http://www.planalto.gov.br/ccivil_03/_Ato2007-2010/2009/Decreto/D6871.htm>. Acesso em: 12 março 2019.

CARdoso, M.G. Produção de Aguardente de Cana de Açúcar. Editora UFLA. LavrasMG, 2011. 241p

FOLEGATTI, Myrtes Maria da Silva. A Imagem da Cachaça no Brasil e no Exterior: Uma Proposta descritiva de Mitos Culturais Brasileiros com Aplicação com PL2E. Disponível em: https://www.maxwell.vrac.puc-rio.br/29483/29483.PDF. Acesso em: 11 abril 2019.

INSTITUTO ADOLFO LUTZ. Normas analíticas do Instituto Adolfo Lutz; métodos químicos e físicos para análise de alimentos. São Paulo, 1977. v.1

MARTINS N.G.S.; MIRANDA M. B., BELLUCO A.E.S.; HORII J., ALCARDE A.R. Qualidade química de cachaças e de aguardentes brasileiras. Ciência e Tecnologia de Alimentos, Campinas, v. 27, n.4, p.897- 901, out.-dez. 2007.

QUEIROZ, J.C.F de; BRITO, A.S.; SOUSA, B.R.S. de; CLEMENTINO, L. da C.; CAVALCANTI, R.M.F.; SOUSA, J.P. de; SILVA, D.P.D. Produção Artesanal de Aguardente a partir de Algaroba (Prosopis julilora) e sua Aceitação de Consumidores. Disponível em: http://www.ufcg.edu.br/revistasaudeeciencia/index.php/RSCUFCG/article/view/198. Acesso em: 27 março 2019.

REZENDE, T.C.; AVELINO, D.O.S.; SILVA, V.N.T. Produção de Aguardente A Partir da Casca de Manga-Rosa (Mangifera Indica L.). Disponível em: <http://www.abq.org.br/cbq/2013/trabalhos/10/2852-16375.html>. Acesso em: 27 março 2019.

VENTURINI FILHO, W.G.; NOGUEIRA, A.M.P. Aguardente de Cana. Disponível em: <http://www.fca.unesp.br/Home/Instituicao/Departamentos/Gestaoetecnologia/Aguardente.pd f>. Acesso em: 27 março 2019. 